\title{
Atypical cutaneous hyperpigmentation after multiple chemotherapy agents
}

\section{Fanny Dessirier ${ }^{1}$, Jean-Philippe Arnault ${ }^{1}$, Isabelle Farre ${ }^{2}$, Claire Poulet ${ }^{3}$, Guillaume Chaby', Motaz Dairi', Catherine Lok ${ }^{1}$}

${ }^{1}$ Department of Dermatology, Amiens University Hospital, Amiens, France, ${ }^{2}$ Department of Pathology, Amiens University Hospital, Amiens, France, ${ }^{3}$ Department of Pneumology, Amiens University Hospital, Amiens, France

Corresponding author: Dr. Fanny Dessirier, E-mail: fanny.dessirier@gmail.com

\begin{abstract}
We report a case of cutaneous hyperpigmentation after injection of cisplatin, carboplatin, pemetrexed, and bevacizumab in patient treated for stage IV lung adenocarcinoma. After the $5^{\text {th }}$ cycle, facial and palmoplantar hyperpigmented macules appeared. The histological examination showed a pigmentary incontinence. The appearance of pigmented palmar macules have been described in association with different chemotherapeutic agents, but to the best of our knowledge an association with the drugs that were administered to our patient have never been described. Photoprotected areas were affected as well as photoexposed zones, an uncommon finding. Post chemotherapy histological and immunohistochemistry studies of such hyperpigmentation have rarely been performed, but in the few studies found, the number of melanocytes was stable. However excessive melanin production in the basal keratinocytes was frequently observed. The pigmentary incontinence could be secondary to an accumulation of drugs in the affected areas by sweat excretion and direct cytotoxicity on the melanocytes.
\end{abstract}

Key words: Pigmentation; Skin toxicity; Chemotherapy

\section{INTRODUCTION}

Anti cancer drugs, chemotherapy, and targeted therapies can cause changes in skin pigmentation, skin appendages, and mucous membranes [1,2].

Skin hyperpigmentation after chemotherapy is common, and many molecules can be involved. The type of hyperpigmentation is not specific to the administered molecule [3].

They can be localized or diffused. More specific hyperpigmentation is sometimes described as eruptions of hyperpigmented macules localized in palmoplantar areas. Although they have mostly been reported after a bullous disease [4] or in the context of immunodeficiency in renal allograft patients [5], they can be associated with chemotherapy.
We report a new case of atypical cutaneous hyperpigmentation that occurred after combination chemotherapy.

\section{CASE REPORT}

A 43-year-old female patient of phototype IV and with a previous history of asthma was treated for stage IV pulmonary adenocarcinoma of the upper right lobe with cerebral, bone, and jejunal metastasis.

The patient was not receiving any long-term treatment or medication and had no known allergies.

She received cisplatin and pemetrexed in the first cycle of treatment, pemetrexed-bevacizumab in $2^{\text {nd }}, 3^{\text {rd }}$, and $4^{\text {th }}$ cycles of treatment, and a carboplatin-pemetrexedbevacizumab combination in the $5^{\text {th }}$ cycle of treatment.

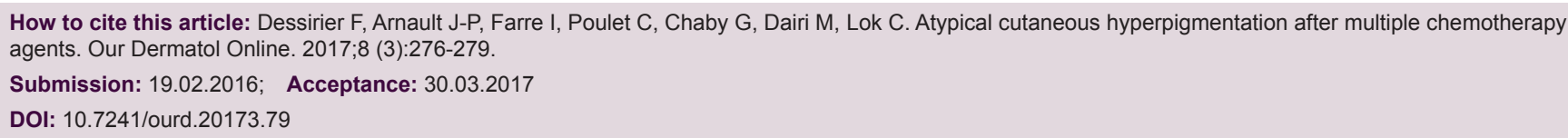


Cerebral and bone metastasis was treated with stereotactic irradiation after the first cycle of treatment.

After the $5^{\text {th }}$ cycle of treatment, asymptomatic pigmented macules appeared on the palms, soles, and face of the patient (Fig. 1). There was no nail or mucosal change. There was no other cause of secondary hyperpigmentation (no abnormality of corticotropic axis present) and no inflammatory skin reactions had preceded chemotherapy.

The dermatoscopic examination showed a homogeneous yellowish-brown pigmentation without melanocytic or vascular structure (Fig. 2).

The histological examination of the skin biopsy showed a pigmentary deposit in the dermis having the appearance of pigmentary incontinence without melanocyte proliferation or inflammation with dystrophic changes in the basal keratinocytes. (Fig. 3).

The pigmented lesions gradually decreased after the cessation of chemotherapy, which allowed a partial regression of the metastasis.

\section{DISCUSSION}

We present a new case of atypical cutaneous hyperpigmentation that occurred after 5 cycles of combination chemotherapy. To the best of our knowledge, an association with the drugs that were administered to our patient have never been described in the literature, thus it is not possible to attribute the finding to a single drug within the combination.

The appearance of pigmented macules has been described in association with 5-fluorouracil (5FU) [6], methotrexate [7], cyclosporin [8], doxorubicin [9], and targeted therapies. One patient treated with $5 \mathrm{FU}$ for gastric adenocarcinoma noticed, one month after chemotherapy, multiple atypical hyperpigmented lumbar macules [6].

Four colorectal cancer patients treated with tegafur (structurally similar to 5FU) have described macular hyperpigmentation limited to the palms, soles, and nails with histological examination revealing epidermal basal hyperpigmentation [10].

Capecitabine (a prodrug of 5FU) has been reported to cause the appearance of reversible acral pigmented macules which disappeared after stopping the drug [11].

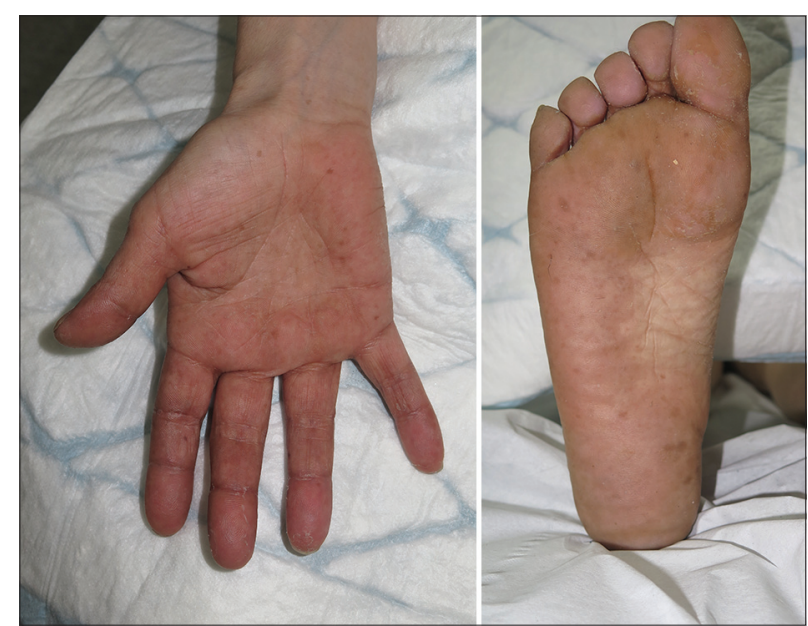

Figure 1: Palmoplantar pigmented macules.

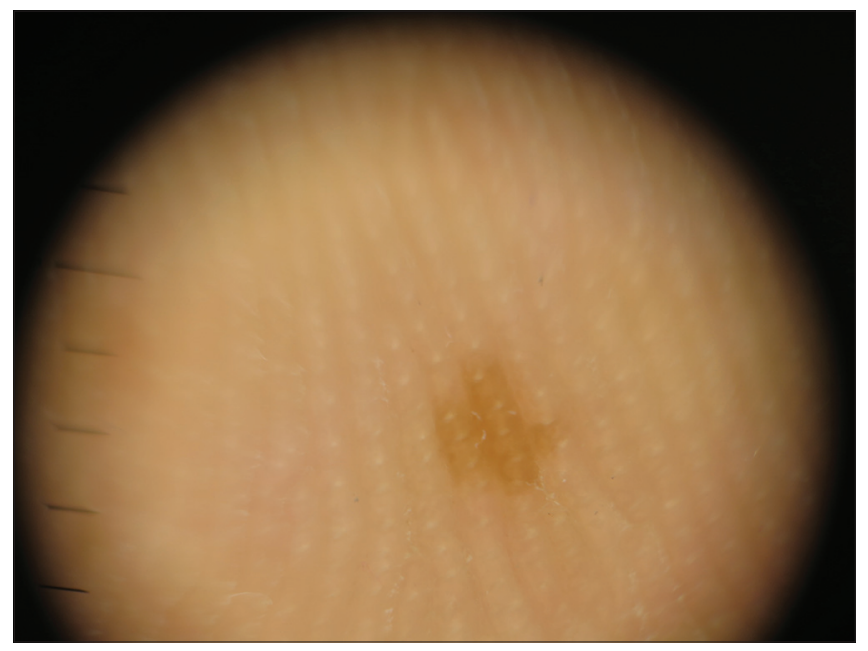

Figure 2: Dermatoscopy exam.

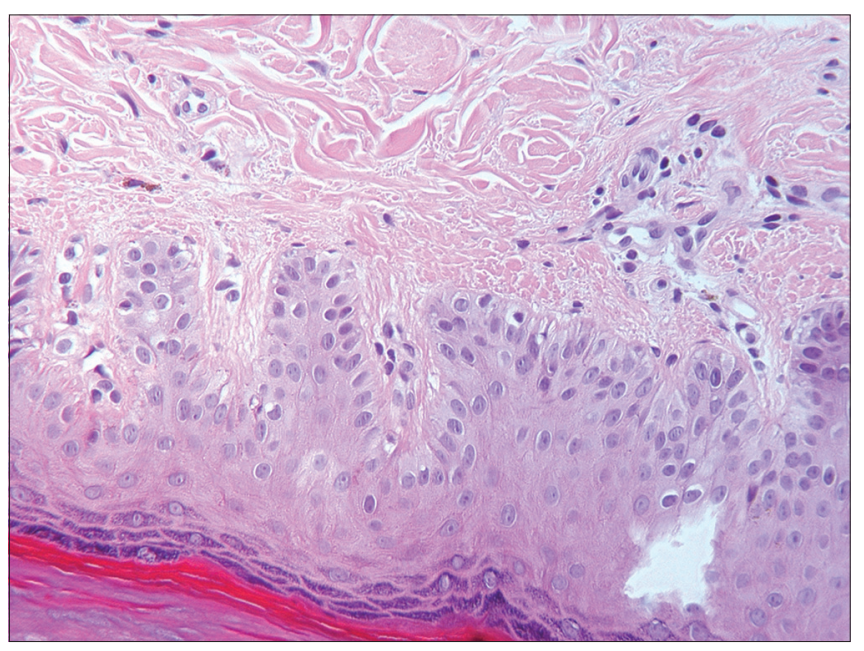

Figure 3: Histology exam: Pigmentary incontinence.

A study showed that the cutaneous toxicity of doxorubicin was a new form of melanotic macules in three patients [9]. 
Our patient was treated with cisplatin, carboplatin, pemetrexed, and bevacizumab.

In the literature, a published case of hyperpigmented skin lesions located on the palmar surface of the hands and the dorsum of the feet was associated with a gemcitabine-carboplatin combination in a patient treated for stage IV non small cell lung carcinoma. The lesion disappeared after stopping the two agents [12].

Platinum salts are known to cause cutaneous skin hyperpigmentation, but to our knowledge no case of hyperpigmention in the shape of macules has been reported so far.

A severe case of hyperpigmentation of the entire integument, sparing the palms of the hands and the soles of the feet, was reported with pemetrexed [13] as well as another case of diffused palmoplantar hyperpigmentation [14]. In addition, no cases of cutaneous hyperpigmentation has been reported following treatment with bevacizumab.

The mechanism of the hyperpigmentation is still poorly understood. These hyperpigmentations appear immediately or may follow an inflammatory erythematous phase. Patients with olive to dark skin are generally more affected, and sun exposure is also a contributing factor.

Photoprotected areas were affected as well as photoexposed zones, an uncommon finding.

However, in the few studies found in the literature, the number of melanocytes is stable. But excessive melanin production in the basal keratinocytes was frequently observed.

Post chemotherapy histological and immunohistochemical studies of such hyperpigmentation have rarely been done, and the number of melanocytes is stable in most of the cases $[15,16]$, Excessive production of melanin was present in basal keratinocytes. Pigmentary incontinence was associated with the presence of dermal melanophages [15]. The palmar pigmented macules caused by $5 \mathrm{FU}$ are the most similar, clinically and histologically, to our case.

Pigmentary incontinence could be secondary to an accumulation of drugs in the affected areas caused by sweat excretion and direct cytotoxicity on the melanocytes and their stimulation.
The use of combination chemotherapy makes it difficult to attribute the effect of each molecule. The hyperpigmentation appears most often after several cycles of chemotherapy. The direct toxic mechanism of the molecules on the melanocytes, with secondary stimulation of melanogenesis, is the most probable mechanism [15].

The tendency to affect palmoplantar areas could be explained by the high proliferation rate of epidermal basal cells, which makes them more sensitive to cytotoxic drugs [17].

In our patient, the pigmented palmoplantar and facial macules were probably linked to the accumulation of the drugs in these affected areas with a toxic effect on the melanocytes and their stimulation. However, further studies are needed to find the exact pathophysiology of hyperpigmentation caused by anti-cancer drugs, particularly in photoprotected areas.

\section{CONCLUSION}

To our knowledge, this is the first case of palmoplantar and facial hyperpigmentation by pigmentary incontinence occurring under cisplatin, carboplatin, pemetrexed, and bevacizumab therapy.

The underlying mechanisms studied are still poorly understood even though these drugs have been in use for many years.

In conclusion, benign macular pigmented lesions can be triggered by combination chemotherapy. Our role is to reassure the patients and emphasize the importance of applying sunscreen and limiting sun exposure.

\section{REFERENCES}

1. Sibaud V, Fricain J-C, Baran R, Robert C. [Pigmentarydisordersinduced by anticancer agents. part I: Chemotherapy]. Ann Dermatol Vénéréol. 2013;140:183-96.

2. O'Doherty CS. Letter: Hyperpigmentation after cancer chemotherapy. Lancet LondEngl. 1975;2:365-6.

3. Koppel RA, Boh EE. Cutaneousreactions to chemotherapeutic agents. Am J Med Sci. 2001;321:327-35.

4. Gelfer A, Rivers JK. Long-termfollow-up of a patient with eruptive melanocytic nevi after Stevens-Johnson syndrome. Arch Dermatol. 2007;143:1555-7.

5. Smith CH, McGregor JM, Barker JN, Morris RW, Rigden SP, MacDonald DM. Excess melanocytic nevi in children with renal allografts. J Am Acad Dermatol. 1993;28:51-5.

6. Rodriguez-Blanco I, Ginarte Val M, Peteiro C, Toribio J. Multiple atypical naevi after systemic 5-fluorouracil. J Eur Acad Dermatol Venereol JEADV. 2007;21:823-5. 


\section{www.odermatol.com}

7. Bovenschen HJ, Tjioe M, Vermaat H, de Hoop D, Witteman BMJ, Janssens RWA, et al. Induction of eruptive benign melanocytic naevi by immune suppressive agents, including biologicals. $\mathrm{Br} \mathrm{J}$ Dermatol. 2006;154:880-4.

8. López V, Molina I, Martín JM, Santonja N, Forner MJ, Jordá E. Eruptive nevi in a patient receiving cyclosporine A for psoriasis treatment. Arch Dermatol. 2010;146:802-4.

9. Lotem M, Hubert A, Lyass O, Goldenhersh MA, Ingber A, Peretz T, et al. Skin toxiceffects of polyethylene glycolcoatedliposomaldoxorubicin. Arch Dermatol. 2000;136:1475-80.

10. Llistosella E, Codina A, Alvarez R, Pujol RM, de Moragas JM. Tegafur-inducedacral hyperpigmentation. Cutis. 1991;48:205-7.

11. Villalón G, Martín JM, Pinazo MI, Calduch L, Alonso V, Jordá E. Focal acral hyperpigmentation in a patient undergoing chemotherapy with capecitabine. Am J Clin Dermatol. 2009;10:261-3.

12. Kleynberg RL, Sofi AA, Chaudhary RT. Hand-foothyperpigmentation skin lesions associated with combination gemcitabine-carboplatin (GemCarbo) therapy. Am J Ther. 2011;18:e261-3.

13. Buchinger K, Stahel R, Niggemeier V, Gubler C, Franzen D. Pemetrexed-induced neutropenicenteritis and severe cutaneous hyperpigmentation in a patient with malignant pleural mesothelioma. Lung Cancer Amst Neth. 2013;80:347-9.

14. Schallier D, Decoster L, de Greve J. Pemetrexed-induced hyperpigmentation of the skin. Anticancer Res. 2011;31:1753-5.

15. Horn TD, Beveridge RA, Egorin MJ, Abeloff MD, Hood AF. Observations and proposedmechanism of N,N',N"-triethylenethiophosphoramide (thiotepa)-induced hyperpigmentation. Arch Dermatol. 1989;125:524-7.

16. Pui JC, Meehan S, Moskovits T. Capecitabine induced cutaneous hyperpigmentation: Report of a case. J Drugs Dermatol. 2002;1:202-5.

17. Milano G, Etienne-Grimaldi M-C, Mari M, Lassalle S, Formento J-L, Francoual M, et al. Candidate mechanisms for capecitabine-related hand-foot syndrome. Br J Clin Pharmacol. 2008;66:88-95.

Copyright by Fanny Dessirier, et al. This is an open-access article distributed under the terms of the Creative Commons Attribution License, which permits unrestricted use, distribution, and reproduction in any medium, provided the original author and source are credited.

Source of Support: Nil, Conflict of Interest: None declared. 